\title{
Retraction Note: minimally invasive versus open surgery for acute Achilles tendon rupture: a systematic review of overlapping meta-analyses
}

Qingbo $\mathrm{Li}^{1}$, Chuanying Wang ${ }^{2^{*}}$, Yanqing Huo ${ }^{1}$, Zhiwei $\mathrm{Jia}^{3^{*}}$ and Xiqian Wang ${ }^{1}$

Retraction Note: the authors have retracted this article [1] because of text overlap with a previously published article [2]. All authors agree to this retraction.

\begin{abstract}
Author details
'Department of Orthopaedic Trauma, The Second Hospital of Shandong University, Jinan, People's Republic of China. ${ }^{2}$ Department of Rehabilitation, The Second Affiliated Hospital of Shandong University of Traditional Chinese Medicine, No.1 Jingba Road, Jinan 250001, People's Republic of China.

${ }^{3}$ Department of Orthopaedics, The 306th Hospital of People's Liberation Army, Beijing, People's Republic of China.
\end{abstract}

Received: 8 June 2018 Accepted: 12 June 2018

Published online: 19 June 2018

\section{References}

1. Li Q, Wang C, Huo Y, Jia Z, Wang X. Minimally invasive versus open surgery for acute Achilles tendon rupture: a systematic review of overlapping meta-analyses. J Orthop Surg Res. 2016;11:65.

2. Zhang $\mathrm{H}$, Tang $\mathrm{H}$, He Q, Wei Q, Tong D, Wang C, Wu D, Wang G, Zhang X,

Ding W, Li D, Ding C, Liu K, Ji F. Medicine. 2016;94(45):e1951.

\footnotetext{
* Correspondence: wangchuanyingjinan@163.com; jiazhiwei@139.com ${ }^{2}$ Department of Rehabilitation, The Second Affiliated Hospital of Shandong University of Traditional Chinese Medicine, No.1 Jingba Road, Jinan 250001, People's Republic of China

${ }^{3}$ Department of Orthopaedics, The 306th Hospital of People's Liberation

Army, Beijing, People's Republic of China

Full list of author information is available at the end of the article
}

(c) The Author(s). 2018 Open Access This article is distributed under the terms of the Creative Commons Attribution 4.0 International License (http://creativecommons.org/licenses/by/4.0/), which permits unrestricted use, distribution, and reproduction in any medium, provided you give appropriate credit to the original author(s) and the source, provide a link to the Creative Commons license, and indicate if changes were made. The Creative Commons Public Domain Dedication waiver (http://creativecommons.org/publicdomain/zero/1.0/) applies to the data made available in this article, unless otherwise stated. 